\title{
A DIALÉTICA NEGATIVA DE ADORNO COMO FILOSOFIA DA POSSIBILIDADE
}

\author{
REAL $^{1}$
}

\author{
ADORNO'S NEGATIVE DIALECTICS AS A PHILOSOPHY OF REAL \\ POSSIBILITY
}

Giovanni Zanotti ${ }^{2}$

(giovanni.zanotti86@gmail.com)

\begin{abstract}
RESUMO
Esse artigo investiga alguns aspectos da dialética materialista de Adorno, com particular atenção a seus Três Estudos sobre Hegel. Enquanto a filosofia de Adorno é lida frequentemente - tanto por críticos habermasianos quanto por leitores mais favoráveis - como uma "crítica da razão instrumental" visando uma mera refutação da tese hegeliana da identidade sujeito-objeto, é sugerido aqui que essa tese desenvolve um papel crucial em Adorno enquanto momento dialético. Em primeiro lugar, é esboçada a visão adorniana da essência objetiva da dialética, implicando que elementos materialistas já estão presentes no próprio Hegel. A possibilidade transcendente da utopia deve ser concebida, portanto, como uma "possibilidade real" fundada na estrutura da experiência imanente. Em seguida, é posta a questão de qual seria, segundo Adorno, o elemento efetivamente falso em Hegel. Através de um exame de alguns conceitos centrais da dialética negativa - a prova ontológica da existência de Deus, o primado do objeto, a contingência do antagonismo, a gênese histórica do Eu freudiano - mostra-se que a crítica adorniana de Hegel é dirigida à ontologização idealista do trabalho, e, portanto, do sujeito - que é, por sua vez, uma forma de trabalho. Finalmente, aponta-se brevemente para um possível resultado prático da dialética negativa, que consistiria na superação do trabalho através do trabalho, ou seja, em uma concepção da abolição da forma-mercadoria que seja dialética, negativa e baseada na aceitação do Estado de direito.
\end{abstract}

Palavras-chave: Dialética Negativa. Materialismo Filosófico. Metapsicologia Freudiana. Prova Ontológica. Crítica Do Trabalho.

\footnotetext{
ABSTRACT

${ }^{1}$ [Publicado pela primeira vez em: “The Lab'sQuarterly", 2017/4, pp. 7-30, com o título: Adorno's Negative Dialectics as a Philosophyof Real Possibility. Tradução de Francisco López Toledo Corrêa.] Esse artigo resume alguns resultados da minha tese de doutorado (Adorno e l'ideadiun'ultima filosofia. Universidade de Pisa: 2016, capítulos 2, 3, 4). Uma primeira versão dele foi apresentada no seminário de História das Teorias Políticas do Departamento de História da Universidade de Bolonha em maio de 2015, e, em seguida, no colóquio internacional "Adorno. Reinvenção da dialética" na Universidade de São Paulo em agosto de 2016. Agradeço aos Professores Raffaele Laudani, Vladimir Safatle, Silvio Rosa Filho, e aos estudantes de Bolonha e São Paulo, pelos úteis comentários e críticas. ${ }^{2}$ Doutor em Filosofia pela Universidade de Pisa. Pós-doutorando no Programa de Pós-Graduação em Filosofia (PPG-FIL) da Universidade de Brasília.

CV Lattes: http://lattes.cnpq.br/8083756301225152.
} 
This article examines some aspects of Adorno's materialist dialectic, by focussing especially on his Hegel: Three Studies. While Adorno's philosophy is commonly read - both by Habermasian critics and more sympathetic readers - as a "critique of instrumental reason" aiming at a mere refutation of Hegel's subject-object identity thesis, it is suggested here that this thesis plays a crucial role in Adorno as a dialectical moment. First Adorno's view of the objective essence of dialectics is outlined, implying that materialist elements are already present in Hegel himself. The trascendent possibility of utopia must be conceived, therefore, as a "real possibility", grounded in the structure of immanent experience. Then the question is posed of what, according to Adorno, is actually false in Hegel. Through a survey on some core concepts of negative dialectics - the ontological proof of God's existence, the object's preponderance, the contingency of antagonism, the historical genesis of the Freudian ego - it is shown that Adorno's critique to Hegel is directed at the idealist ontologization of labor, and therefore, of subject - itself a form of labor. Finally, a possible pratical outcome of negative dialectics is briefly hinted at, consisting in the overcoming of labor through labor, i.e., in a conception of the abolition of the commodity form that is dialectical, negative, and based on the acceptance of the rule of law.

Palavras-chave: Negative Dialectics, Philosophical Materialism, Freudian Metapsychology, Ontological Proof, Critique Of Labor.

A grande dificuldade aqui é não apresentar a coisa assim, como se não se pudesse fazer algo. (L. Wittgenstein, Investigações filosóficas)

A relevância da filosofia clássica alemã em geral, e de Hegel em particular, para o pensamento de Adorno foi sublinhada com insistência crescente nos últimos anos, em debates científicos tanto de língua alemã quanto de língua inglesa ${ }^{3}$. O objetivo desse artigo é oferecer uma contribuição na mesma direção. Por um lado, será mostrado que, embora a palavra final de Adorno seja a crítica da "tese da identidade", o peso dessa tese enquanto momento dialético, na filosofia dele, é muito maior do que é normalmente reconhecido. Particular atenção será dedicada, nesse sentido, a seus importantíssimos Três Estudos sobre Hegel. Por outro lado, será sugerido que, nessa nova perspectiva, a crítica adorniana do idealismo de Hegel pode aparecer, por sua vez, de forma diferente e mais adequada. Trata-se, aqui, apenas de uma tentativa esquemática e panorâmica de reconstrução teórica de algumas linhas essenciais na dialética negativa, tentativa esta que deveria servir como base para desenvolvimentos ulteriores.

\footnotetext{
${ }^{3}$ Dentro de muitas outras contribuições, veja-se, em particular, a redescoberta da epistemologia de Adorno em O' Connor 2004, e, no mesmo sentido, Sherratt 2007 e Bowie 2013. Mais recentemente, Sommer 2016 estendeu a análise epistemológica à dimensão da filosofia da história. Nuzzo 2008 contém observações consideráveis em uma perspectiva hegeliana. Para uma lista geral e constantemente atualizada de literatura secundária sobre Adorno, cf. a bibliografia online publicada pelo "Núcleo de Pesquisa Adorno" da Universidade de Oldenburg: https://www.uni-oldenburg.de/fileadmin/user_upload/philosophie/download/Forschung/Internationale_Adorno-Bibliographie_Stand_April_2012.pdf.
} 


\section{UMA PREMISSA HISTÓRICA}

Comecemos por algumas citações célebres daquele autor que ainda permanece, de longe, o mais influente leitor de Adorno:

A dialética negativa deve ser entendida [...] como um mero exercício. [...] A filosofia que se retira, atrás das linhas do pensamento discursivo, para a "rememoração da natureza", paga pela força despertadora do seu exercício o preço da renúncia ao objetivo do conhecimento teórico. (Habermas 1999, 4902)

A suspeita de ideologia torna-se total [...]. Ela volta-se não apenas contra a função irracional dos ideais burgueses, como também contra o próprio potencial racional da cultura burguesa. (Habermas 2000, 169)

Dialética negativa e teoria estética já podem apenas "remeter, de forma impotente, uma à outra". (Habermas 1999, 490)

Essas frases desenham uma paisagem familiar. Não exprimem apenas uma interpretação, embora muito influente, mas contêm em si um fragmento de história no sentido mais literal. Em seus Três Estudos sobre Hegel, Adorno recupera a ideia benjaminiana do "amadurecimento póstumo" (Nachreife): "Mesmo os pensamentos outrora firmemente cunhados possuem uma história de sua verdade, e não mera sobrevida; eles não permanecem em si indiferentes ao que lhes sucedeu" (Adorno 2015a, 93) ${ }^{4}$. Se, cinquenta anos após a publicação da Dialética negativa, pergunta-se sobre o que o pensamento de Adorno tornou-se, a situação parece singular. Ele muito prontamente desapareceu da cena filosófica, podado em seu florescimento por aqueles mesmos que pareciam seus herdeiros legítimos, os quais o identificaram, afinal, como uma espécie de predecessor do estilo de pensamento "pósmoderno". Mas precisamente tal estilo, entrementes, triunfou em boa parte do mundo filosófico. Não vamos discutir aqui a interpretação de Habermas: enquanto a consideramos errada, também acreditamos que ainda necessite de uma refutação adequada à sua grandeza. Observamos apenas duas coisas. Em primeiro lugar, a imagem de Adorno que emerge da descrição habermasiana é, de fato, largamente partilhada. Os traços que Habermas critica são os mesmos que os adornianos frequentemente reivindicam: o primado do estético; a insistência sobre a dimensão, estetizante mesmo (ou seja, romântica), do fragmento, do paradoxo, do jogo, da ironia, da "contradição performativa" (Habermas 2000, 170); a apologia do particular e do plural; a desconfiança da razão científica, e geralmente, do “potencial de 
racionalidade dos ideais burgueses"; a retirada, a rendição, a escolha voluntária da "impotência" como recusa a comprometer-se com o poder - o poder sublimado do conceito, o poder material do Estado 5 . Tudo o que é hoje clichê. Se tudo isso teve uma força crítica no passado, ela foi perdida há muito tempo com sua difusão universal. Sem dúvidas, o próprio Adorno, em muitos casos, acentuou justamente tais aspectos da sua filosofia; mas é sempre Adorno que lembra, no último dos Três Estudos (Skoteinos), que "na vida póstuma das obras filosóficas, o desdobramento de seu conteúdo liberta gradualmente aquilo que elas expressam do que foi meramente pensado" (Adorno 2015a, 150). Certos estratos interpretativos que por muito tempo recobriram o pensamento de Adorno, como uma mortalha, poderiam estar prontos a cair ${ }^{6}$.

Tal caída poderia dar resultados muito surpreendentes. De fato - e esse é o segundo ponto - o filósofo que, no Discurso filosófico da modernidade, reprova seu mestre pela falta de "saídas" (Habermas 2000, 183) é o mesmo que pronuncia com desenvoltura frases como esta: "Abandonei, ao menos no que diz respeito a mim, a pretensão filosófica enfática da verdade" (Habermas 1985, 207) ${ }^{7}$. Ao lê-lo com atenção, todo o pensamento de Habermas revela - pelo menos como um dos seus momentos - um profundo sentimento de resignação. O espírito do auto-proclamado "pensamento pós-metafísico lembra, às vezes, daquele afeto que Adorno tinha identificado em Lukács (não por acaso, o outro grande crítico "progressista” de Nietzsche) como o afeto de alguém que "desesperadamente chacoalha suas correntes imaginando que o seu barulho seja a marcha do espírito do mundo" (Adorno 1991, 239). E se a acusação de pessimismo fosse, na verdade, uma projeção? Mas se for assim, então, seguindo o mecanismo do recalque, deveríamos esperar uma reversão. O pensamento de Adorno, libertado de sua casca "negra", poderia não ser apenas diferente: poderia ser o exato contrário.

Se os tempos estão maduros para reler Adorno com novos olhos, essa mesma possibilidade está historicamente determinada. São os eventos históricos de nosso presente que abalaram a certeza aparente de princípios amplamente partilhados não apenas no interior do Instituto frankfurtiano, como, mais geralmente, no debate filosófico inteiro dos últimos cinquenta anos. Aqui gostaríamos de sugerir uma hipótese meramente preliminar: as duas principais facções da filosofia crítica depois da morte de Adorno (o que ao mesmo tempo

\footnotetext{
${ }^{5}$ Outra famosa formulação da crítica de Habermas é sua afirmação de que Horkheimer e Adorno "renunciam à teoria e praticam ad hoc a negação determinada" (Habermas 2000, 183). Dito de passagem, essa objeção soa bastante curiosa, pois pertence à definição da negação determinada ser sempre ad hoc, ou seja, relativa a um conteúdo específico.

${ }^{6}$ Para uma exposição convincente de como a dialética negativa aparece do ponto de vista retrospectivo da hegemonia intelectual pós-moderna, $c f$. Petrucciani 2004.

7 "Ich habe, jedenfallsfürmichselber,

den
} 
significa: depois de sessenta e oito) representam na realidade duas faces da mesma moeda, por uma precisa razão material. Trata-se, por um lado, dos desenvolvimentos da teoria crítica sucessivos à "virada comunicativa", e por outro, daquela variada constelação filosófica que é normalmente designada como "French theory", e que talvez seja melhor identificada pelo termo "ideologia francesa" $"$. Ambos, de fato, repousam sobre um fundamento real que se torna visível apenas hoje, no momento de seu colapso. É o Estado do bem-estar social europeu. Uns teorizaram-no abertamente, enquanto que os outros foram acomodados, por assim dizer, em seus interstícios ${ }^{9}$. Se agora perguntamos por qual é a premissa subentendida ao ideal social democrata, e qual a sua forma filosófica de reflexão, podemos, com o Adorno dos Escritos sociológicos, dar a seguinte resposta: é o pressuposto idealista de uma continuidade entre consciência e mundo, ou seja, entre sujeito e sociedade ${ }^{10}$. O conceito da objetividade social como sistema das leis dinâmicas do capital, um sistema produzido e reproduzido pelos seres humanos, e revogável por eles próprios, mas ao mesmo tempo alienado e independente da vontade deles, singular ou associada, e destinado, cedo ou tarde, a aniquilar suas melhores intenções subjetivas - este conceito é propriamente o que estraga a festa ${ }^{11}$. A necessidade de recalcar essa objetividade é projetada filosoficamente na necessidade de recalcar a objetividade como tal. Por isso, ao ceticismo explícito das mais recentes variantes do construtivismo se opõe o ceticismo implícito, mal disfarçado, que resolve a objetividade no "acordo intersubjetivo" enquanto, contra o próprio conceito de "comunicação", Adorno objeta já nas primeiras páginas da Dialética negativa: "A verdade é objetiva e não plausível” (Adorno 2009, 43). O termo “ideologia", em seu sentido marxiano estrito, é apropriado aqui. Com efeito, o recalque da objetividade é a proibição da experiência, e por isso autoritário. As leis da "segunda natureza" se encarregaram, pois, de tornar evidente tal resultado: a crise econômica varreu a base do que ainda ontem era considerado progressivo. A responsabilidade frente ao risco de uma recaída na barbárie possui, então, o seu momento teórico: a reflexão da filosofia sobre suas próprias deficiências.

\section{PATHOS DA OBJETIVIDADE}

\footnotetext{
${ }^{8}$ A expressão é utilizada em seu sentido especificamente marxiano em Arantes 1990.

${ }^{9}$ Devo essa intuição a Manfred Posani.

${ }^{10} \mathrm{Cf}$. em particular Adorno 2015b, 71-135.

${ }^{11} \mathrm{Cf}$. Reichelt 2008.
} 
Isso significa - tal como é frequente em períodos de transição - voltar a Hegel. Porque a questão de Hegel, ao menos para Adorno, é a questão da objetividade: de como a consciência, sem renunciar à reflexão iluminada sobre suas próprias mediações - afinal, sobre sua finitude - possa, entretanto, conseguir alcançar a coisa em si. Em um ensaio de Palavras e sinais, Adorno invoca a "liberdade para o saber que não se encontre já implícito": "O pensar filosófico só começa quando não se contenta com conhecimentos que se deixam prever e dos quais nada mais se retira além daquilo que se colocou neles" (Adorno 1995, 16) ${ }^{12}$. Todo o pensamento de Adorno é permeado pela oposição entre a "reduplicação tautológica" do sujeito e o "novo" como elemento material, coisal, o objeto que está em si e fala a partir de si, está na consciência, mas não se limita a esta ${ }^{13}$. "Leibhaftig", "auswendig", "rauschen”, "spiritueller Leib”, "das volle Leben noch einmal": no grandioso final do primeiro dos Três Estudos (Aspectos da filosofia hegeliana), o estilo se tende até o espasmódico e os termos se multiplicam, na tentativa de circunscrever, juntos, esta mesma ideia fundamental do "em carne e osso" (Adorno 2015a, 89-90). Ela é atribuída a Hegel, que como nenhum filósofo antes dele haveria atingido a "sublimação". Em Adorno, esse termo conserva o significado freudiano - espiritualização do impulso material - mas designa também, ao mesmo tempo, o movimento oposto: a alienação completa da consciência no objeto, o fazer-se corpo do espírito. "Essa alienação é testemunhada pelo gesto doloroso de Hegel, pelo semblante de quem pensou, pelo semblante desgastado daqueles que literalmente se reduziram às cinzas" (Adorno 2015a, 89). Novamente, neste pathos da objetividade há o eco de Benjamin: é seu, em particular, o esquema pelo qual a intenção subjetiva transcende a si mesma a partir de dentro, não obstante, mas em virtude de seu máximo esforço, até “apagar" no "não-intencional”, na coisa (o verbo erlöschen, usado repetidamente nos Três Estudos, remete ao ensaio de Benjamin sobre a tradução ${ }^{14}$ ).

A contribuição específica de Adorno foi ter entendido que esse mesmo movimento já pertencia à dialética hegeliana. Pois haveria em Hegel tanto a autorreflexão da consciência, herança da crítica kantiana, quanto também "o sonho da verdade própria da coisa" (Adorno 2015a, 103): ou, como Adorno diz nas lições Introdução à dialética, a "quadratura do círculo" hegeliana consiste em fazer plena justiça, simultaneamente, ao momento de verdade tanto do racionalismo como do irracionalismo (Adorno 2010, 59). Ao longo dos Três Estudos, Adorno se movimenta entre esses dois polos, e se poderia quase dizer que o gesto peculiar de seu pensamento, em geral, consiste no próprio fato de que ambos os momentos são mantidos até o

\footnotetext{
12 Tradução alterada.

${ }^{13} \mathrm{Cf}$. O' Connor 2004, capítulos 2-3.

${ }^{14} \mathrm{Cf}$. Adorno 2015a, 58, 89, 150; Benjamin 2008, 63.
} 
final, em seu pleno direito respectivo. É interessante que um dos termos preferidos pela teoria crítica pós-adorniana aparece muito raramente em Adorno: o adjetivo "paradoxal". O motivo é claro: o paradoxo - que é um conceito do existencialismo - é a contradição sem a dialética ou, como diz Adorno no segundo estudo (Teor de experiência), a dialética é o paradoxo dominado, "desdobrado" (Adorno 2015a, 104). Na interpretação que pretendeu liquidar a dialética negativa, o grande ausente é nada menos do que a própria dialética. Habermas não perde tempo perguntando-se como é possível que, em Adorno, o filósofo da identidade por excelência tornase o padroeiro da não-identidade. Porém, justamente com esta surpreendente tese historiográfica abrem-se os Três Estudos: o idealista Hegel é ao mesmo tempo o primeiro materialista e, em um certo sentido, também o último, ao menos entre os filósofos no sentido estrito. Adorno não reivindica a atualidade de Hegel, mas sua novidade: o excesso da dialética em relação às várias formas do pensamento sucessivo. A tentativa declarada dos Três Estudos é "traduzir numa experiência contemporânea possível o que surge como essencial para [Hegel], o que ele viu no mundo" (Adorno 2015a, 92). Se perguntamos, portanto, sobre o que Adorno viu em Hegel, talvez a melhor resposta se encontre em uma das passagens mais belas dos Três Estudos. O filósofo que Rahel Jaeggi define com a fórmula "atmosfera tétrica e sem saída [düster-ausweglose Stimmung]” (Jaeggi 2005, 118) é o mesmo que escreve estas palavras:

[A filosofia em Hegel] não quer se deixar intimidar, abrir mão da esperança de aperceber aquele todo da realidade bem como o conteúdo que a ciência institucionalizada lhe coibiu em nome dos achados válidos, à prova de tudo. Hegel percebeu o caráter regressivo e brutal da humildade kantiana, sublevando-se contra a conhecida sentença na qual o esclarecimento de Kant se congraça com o obscurantismo: "Portanto, tive que suprimir o saber para obter lugar para a fé, e o dogmatismo da Metafísica, isto é, o preconceito de progredir nela sem Crítica da razão pura, é a verdadeira fonte de toda a sempre muito dogmática incredulidade antagonizando a moralidade". A antítese de Hegel diz o seguinte: "A essência fechada do universo não possui nenhuma força em si que pudesse fornecer resistência à coragem do conhecimento, ela deve se abrir diante dele e tornar claras sua riqueza e suas profundezas e oferecê-las ao seu prazer". Em tais formulações, o baconiano pathos primordial burguês amplia-se àquele da humanidade emancipada: pode ainda dar certo [da $\beta$ es dochnochgelinge]. Face à resignação da época atual, esse impulso fundamenta a verdadeira atualidade de Hegel. ${ }^{15}$ (Adorno 2015a, 1012)

A força que emana desta passagem faria empalidecer um "filósofo da afirmação", porque é precisamente a força da negação determinada: aquela que o filósofo "tétrico e sem saída" chamava a "extraordinária liberdade, a superioridade quase lúdica que o

15 Tradução alterada. 
pensamento dialético contém" (Adorno 2010, 102) ${ }^{16}$. Nunca tanto como nos Três Estudos Adorno mostra o jogo, se abandona com igual fervor, contra a "resignação do tempo presente", ao "pathos da humanidade emancipada"- ou seja, nunca ele é tão iluminista. Nas próximas páginas, pois, buscaremos nesse texto uma chave possível para uma leitura alternativa do pensamento adorniano: partiremos dos Três Estudos (em particular os dois primeiros) para depois expandirmos a perspectiva sobre a dialética negativa no seu conjunto. Não podemos expor aqui uma interpretação completa, mas apenas jogar luz sob alguns aspectos essenciais, embora de modo geral e fragmentário.

\section{O MATERALISTA HEGEL}

O primeiro e segundo estudos são, por assim dizer, sinópticos. Ambos se iniciam com uma majestosa defesa de Hegel contra o preconceito, e em ambos esta tonalidade domina quase até o final, para dar lugar, apenas nas últimas páginas, a uma virada crítica: malgrado tudo, Hegel é falso. $\mathrm{O}$ argumento segue a mesma estrutura nos dois textos: a força do pensamento hegeliano está no "escândalo" e não no "plausível” (Adorno 2015a, 112), na construção do sujeito-objeto e não em um suposto "senso de realidade" (a referência polêmica é a Nicolai Hartmann). Hegel, em suma, pensa concretamente não a despeito, mas em virtude do momento especulativo. Podemos então corrigir a afirmação precedente: não apenas o idealista Hegel é também um materialista, mas é o seu próprio idealismo que interverte no materialismo e tornao possível. Esta é a verdadeira originalidade das análises de Adorno frente a outros pensadores marxistas, mesmo aqueles mais bem-dispostos com Hegel: Adorno não defende o "método dialético" separado do "sistema do idealismo" e "colocado novamente de pé", mas uma dialética interna ao próprio idealismo. E o conteúdo desta dialética está expresso da melhor maneira na continuação do passo citado anteriormente: "O extremo idealista [...] tem suas implicações materialistas [...] Hegel se aproxima do materialismo social tanto mais ele impulsiona o idealismo adiante também para o campo da teoria do conhecimento, tanto mais ele insiste contra Kant em compreender os objetos a partir do interior” (Adorno 2015a, 102).

O resíduo "obscurantista” em Kant consistiria na própria proibição desta compreensão "a partir do interior": a proibição irracional de tocar a coisa. Em outras palavras, somente a

\footnotetext{
16 "[Die] merkwürdig[e] Freiheit, [die] fastspielerisch[e] Überlegenheit, die in demdialektischenDenkennuneinmalenthaltenist". (Tradução nossa)
} 
distinção entre essência e aparência torna possível a crítica; e somente a posição da identidade torna possível ao pensamento de conhecer uma essência além dos fenômenos. O movimento da contradição é aquele no qual a coisa "em carne e osso" continuamente despedaça o curso linear, e por assim dizer autista, da dedução subjetiva; mas ele pode fazê-lo porque o objeto tambémem algum sentido - é espírito. $\mathrm{O}$ objeto tem uma afinidade fundamental com o sujeito, sua própria vida coincide com aquilo que Hegel chama de "a certeza de si próprio"; e somente por isso o objeto pode falar a partir de si, em vez de reduzir-se à matéria prima ou projeção do sujeito: "Uma vez que o objeto torna-se sujeito no absoluto, ele não é mais inferior face ao sujeito. Em seu extremo, a identidade torna-se agente do não-idêntico" (Adorno 2015a, 103).

Neste ponto, no entanto, impõe-se a pergunta mais clássica, ingênua, e, todavia, inevitável: o quê, precisamente, é falso em Hegel? Adorno, como se sabe, recusa a tese da identidade. Mas, à luz das considerações precedentes, como deve ser interpretada essa recusa? Notamos uma circunstância geral. As críticas de Hegel, mesmo as de esquerda, normalmente sofrem de uma fraqueza peculiar, contra a qual é jogo fácil para qualquer hegeliano: tendem a recair aquém de Hegel porque trocam-no por Fichte (ou por Gentile). De fato, as acusações mais frequentes (subjetivismo, panlogismo, logocentrismo, o espírito que cria o mundo e similares) confundem o resultado final da construção hegeliana (o saber absoluto ou a Ideia) com a posição inicial da subjetividade abstrata, separada, "apenas subjetiva", que aquela construção precisamente tem como tarefa superar. Ora, em Adorno acontece algo estranho. Se, de um lado, como vimos, toda a argumentação tenta refutar aqueles clichês, quando se chega ao âmago da questão, e se trata de acertar as contas com Hegel, é como se houvesse uma queda repentina da voltagem teórica: as formulações de Adorno - por exemplo, aquela célebre: “o sujeito-objeto hegeliano é sujeito" (Adorno 2015a, 63) - permanecem vagas e fugidias, parecendo realinhar-se às posições da esquerda hegeliana, como se Hegel tivesse vencido mais uma vez.

O mesmo problema pode ser formulado de outro modo. Em Aspectos, Adorno menciona um conceito que estará no centro da Dialética negativa, o do "bloco" kantiano (a cisão entre sujeito e objeto), e interpreta assim o progresso de Hegel, o elemento genuinamente "nãokantiano" de seu pensamento: "Nós, ao aferrarmos conceitualmente o bloco, o limite que é posto à subjetividade, ao reconhecê-la como "mera" subjetividade, estamos já além do limite" (Adorno 2015a, 57) ${ }^{17}$. Cada limite, tão logo é reconhecido como tal, é por princípio superável: alude a isso também a passagem da Enciclopédia hegeliana sobre a "essência fechada

\footnotetext{
${ }^{17}$ Tradução alterada.
} 
do universo". Para Adorno, isso significa que o "teor de experiência" mais íntimo do pensamento hegeliano, seu núcleo histórico real, é o burguês liberto dos vínculos feudais, reconhecidos em sua irracionalidade: o trabalho liberto. Bem, se é para dar certo a refutação de Hegel, deve-se usar suas próprias armas: deve-se mostrar que a fome hegeliana de objetividade não é muito temerária, mas muito pouco; que em Hegel permanece um "bloco", um superego, uma proibição residual. A pergunta então vira: qual o limite de Hegel?

Antecipamos já a solução: se há em Hegel o trabalho liberto, todavia não há espaço para a libertação do trabalho. A nossa hipótese é de que, em Adorno, essa solução já se dá integralmente, mas que para encontrá-la é necessário - digamos assim - um percurso mais longo. Tentemos dar aqui, pelo menos, uma ideia geral.

\title{
4. O CENTRO DA REFLEXÃO FILOSÓFICA
}

Há uma passagem em Aspectos que é simétrica àquela de Teor de experiência já citada. $\mathrm{O}$ argumento é o mesmo:

\begin{abstract}
O rigor da tentativa de Hegel em resgatar a prova ontológica da existência de Deus contra Kant pode ser posto em dúvida. Mas o que o induziu a isso não foi vontade de obscurecer a razão, pelo contrário, foi a esperança utópica de que a barreira das "fronteiras da possibilidade da experiência" não fosse a última; que não obstante, como na cena final do Fausto, se lograsse sucesso $[d a \beta$ es doch... gelinge]; que em todas as suas fraquezas, limitação e negatividade, o espírito se assemelhasse à verdade, e por isso estivesse apto ao conhecimento da verdade. Se anteriormente, com razão, a presunção da doutrina hegeliana do espírito absoluto fora salientada, hoje, ao contrário, já que o idealismo é difamado por todos e especialmente pelos cripto-idealistas, um salutar corretivo vem da representação do caráter absoluto do espírito. Isso se dirige à paralisante resignação da consciência contemporânea, por sua fraqueza sempre pronta a corroborar com a própria humilhação realizada através da preponderância da existência cega (Adorno 2015a, 83).
\end{abstract}

Como na outra passagem, retorna aqui o verbo gelingen ("dar certo"), e a sintaxe também é a mesma. O pathos da filosofia hegeliana seria a confiança "daß es gelinge": literalmente, "que a coisa dê certo". Esta forma impessoal alarde. Que dê certo o quê? O conteúdo não é especificado, mas permanece, por assim dizer, intransitivo, a ideia pura e simples de um cumprimento. Disso é dito somente que, por ser tal, deveria ser absoluto: tal como na cena final do Fausto, onde o momento é chamado a parar porque é apenas belo, não mais sulcado por alguma negatividade. Parece que Adorno 
toca aqui o ápice do utopismo abstrato: a transcendência é de tal maneira distante que não sabemos nem com certeza sobre que falamos. E a isso mesmo alude também o problema mencionado no início da passagem: a prova ontológica da existência de Deus.

Este último é um tema que ocorre no último Adorno com crescente insistência. $\mathrm{Na}$ Terminologia Filosófica, ele diz sobre a prova ontológica: "parece-me cada vez mais [...] como o centro da reflexão filosófica” (Adorno 1973, 97-8) ${ }^{18}$. Na seção final da Dialética negativa, é definida "vã" a retomada hegeliana da prova ontológica depois da refutação kantiana (Adorno 2009, 333). De fato, a prova ontológica, desde Anselmo, conclui diretamente a partir do pensamento do absoluto à sua existência, e por isso pressupõe a identidade, a redução de toda transcendência à imanência lógica. Entretanto, algumas páginas antes, na seção intitulada: “A ânsia de salvar e o bloco", Adorno diz de Kant: "O segredo de sua filosofia é a impossibilidade de pensar o desespero até o fim [...]. Sua filosofia gira, como aliás certamente toda filosofia, em torno da prova ontológica da existência de Deus" (Adorno 2009, 319). "Como toda filosofia": também, portanto, a dialética negativa. Nas Notas de literatura, ao final dos "Pequenos comentários a Proust", Adorno cita uma frase de Em Busca do Tempo Perdido sobre a morte do poeta Bergotte. Escreve Proust: "O pensamento de que Bergotte não está morto para sempre [...] não é completamente incrível". Adorno comenta (e o mesmo argumento será retomado no parágrafo da Dialética negativa sobre a "ânsia de salvar"): a experiência que motiva essa reflexão seria "comparável ao que é feito nas grandes obras de arte: é impossível que seu conteúdo não seja verdadeiro; que seu sucesso e mesmo sua autenticidade não se referem à realidade que elas garantem" (Adorno 1991, 183). "Sucesso" é “Gelingen”. Prossegue Adorno: "a confiança de Proust na força objetiva do sucesso da obra [novamente Gelingen, G.Z.]" refere-se a este pensamento, "última, pálida, secularizada e, todavia, inextinguível sombra da prova ontológica de Deus" (ibid.).

Adorno nunca diz que a prova ontológica é verdadeira: pelo contrário. Mas parece que, para exprimir-se com Marx, um "núcleo racional” nela pode ser salvado. O problema pode ser formulado nos termos seguintes. Se, para Adorno, diferentemente de Hegel, o Absoluto não está já dado, mas é transferido para a experiência futura como pura possibilidade ("dass es gelinge"), então a questão da prova ontológica torna-se a questão de uma ponte entre o presente a utopia, da realidade da possibilidade em um sentido diferente da "possibilidade real" hegeliana, que Adorno critica. Se para Hegel - e para Lukács - “apenas seria possível aquilo

18 “...eineFrage, die mirselber, jemehrichnachdenke, überhauptalsZentrum der philosophischenBesinnungerscheint: das ProblemdessogenanntenontologischenGottesbeweises". (Tradução nossa) 
que de fato se tornou real" (Adorno 2015a, 112), trata-se, agora, de manter a possibilidade como possibilidade, e, todavia, encontrar um fundamento dela na existência real: em suma, salvar, ao mesmo tempo, Kant e Hegel. A bem ver, aqui está o sumo das objeções de Habermas: a crítica "minaria seus próprios fundamentos" precisamente porque, tornando-se "total", não teria mais à disposição um critério normativo dado na experiência atual. A ideia de Adorno parece ser esta: existem experiências nas quais o objeto, a natureza, o em si, é realmente alcançado, está presente "em carne e osso"- experiências estéticas como em Proust, mas as passagens sobre a sublimação em Aspectos nos dão a entender que, ao menos no caso de Hegel, o conhecimento conceitual também foi capaz de ir tão longe. Com Hegel, tais experiências não são meros fenômenos; contra Hegel, não são ainda o absoluto, a possibilidade que nunca foi realizada. Os momentos nos quais o sujeito toca a coisa são e não são ao mesmo tempo “o sucesso". Como é possível?

\section{PRIMADO DO OBJETO E CONTINGÊNCIA DO ANTAGONISMO}

Tal como frequentemente ocorre em Adorno, a resposta encontra-se em Marx. No final dos anos vinte, o diretor do Instituto Marx-Engels em Moscou e editor da Marx-Engels Gesamtausgabe, David Ryazanov, então expurgado por Stalin, enviou ao Instituto frankfurtiano um pacote de inéditos marxianos. Eram os Manuscritos econômicos-filosóficos de 1844. Foram publicados poucos anos depois, e imediatamente resenhados por Marcuse em um famoso ensaio $^{19}$. Ao lado das notórias páginas sobre trabalho alienado encontramos aqui, no terceiro manuscrito dedicado à crítica de Hegel, o esboço de uma teoria não menos importante, formulada por Marx sob influência de Feuerbach e retomada, entre outros, pelo último MerleauPonty: a teoria do "ser objetivo" (gegeständlichesWesen). Ela afirma, essencialmente, que para que um sujeito seja um tal, para poder haver um objeto, ele tem de ser ele próprio objeto, pertencer à objetividade:

O ser objetivo atua objetivamente e não atuaria objetivamente se o objetivo não estivesse posto em sua determinação essencial. Ele cria, assenta apenas objetos, porque ele é assentado mediante esses objetos, porque é, desde a origem, natureza. [...] É idêntico: ser objetivo, natural, sensível e

${ }^{19} \mathrm{Cf}$. Buck-Morss 1977, 31, 215 nota. 
ao mesmo tempo ter fora de si objeto, natureza, sentido, ou ser objeto mesmo, natureza, sentido para um terceiro. [...] Tão logo eu tenha um objeto, este objeto tem a mim como objeto. (Marx 2004, 126-8)

É provável que Adorno, com nem trinta anos de idade, tenha sido um dos primeiros de todos a ler estas palavras. Quarenta anos depois, nos parágrafos mais densos da Dialética negativa, a tese central da obra - o "primado do objeto"-é ilustrada com frases como estas:

Toda afirmação de que a subjetividade "é" de um modo ou de outro já inclui uma objetividade [...]. É somente porque o sujeito é por sua vez mediado, ou seja, porque ele não é o elemento radicalmente outro em relação ao objeto que apenas o legitima, que ele é capaz de apreender a objetividade em geral. (Adorno 2009, 159)

Aquele para o qual algo é dado pertence a priori à mesma esfera daquilo que lhe é dado. (ivi, 168)

É somente na medida em que esse momento também é por sua vez não-eu que o eu se comporta em relação ao não-eu, "faz" algo, e isso mesmo se o fazer fosse pensamento. (ivi, 172)

Geneticamente, a consciência autonomizada, a suma conceitual daquilo que é ativo nas performances do conhecimento, é derivada da energia libidinal do ser genérico homem (der libidinösenEnergiedesGattungswesensMensch). (ivi, 159)

O nexo é evidente. A tese do primado do objeto parece descender diretamente daquela do "ser objetivo". A condição que torna possível o conhecimento objetivo - o fato do sujeito ser, por sua vez, um objeto - é a mesma que refuta o idealismo: que desmente a concepção da subjetividade como um elemento ontologicamente último, "radicalmente outro", um em-si. Pelo contrário, o sujeito é possível somente como uma modalidade da objetividade. Isso tem consequências bem concretas, que já estão implícitas na ideia marxiana de uma "realização prática" da filosofia, e que, entretanto - esta é a nossa hipótese -, emergem no próprio pleno significado apenas com Adorno. Ao mesmo tempo, e vice-versa, a partir deste ponto poderia aparecer sob uma nova luz o papel de Adorno na história da filosofia. A última das afirmações citadas, na qual o conceito marxiano de Gattungswesen é aproximado àquele de "energia libidinal", indica a direção para onde buscar.

Na Dialética do Esclarecimento, como se sabe, a subjetividade como tal - como unificação violenta do múltiplo natural- é desmascarada em seu caráter de domínio: até em suas instâncias mais abstratas, as formas lógicas da verdade. Mas, se isso 
fosse tudo, seria uma mera repetição de argumentos nietzschianos. Em vez disso, Horkheimer e Adorno fazem muito mais: com uma autêntica apropriação marxista de Nietzsche, fecundam a crítica da subjetividade e da razão com a intuição em absoluto mais revolucionária de Marx, a do caráter material, e, portanto, contingente, do antagonismo. Cada cisão interna à consciência, e a própria cisão entre consciência e realidade, não têm, por sua vez, origem na consciência, como uma espécie de pecado original dela, nem - por consequência - podem ser resolvidas no seu espaço fechado, como todo idealismo, apologeticamente, pressupõe. Pelo contrário, a separação entre sujeito e objeto está fundada objetivamente, em uma cisão digamos assim - interna à matéria: a violência imediata da primeira natureza, e a violência abstrata, impessoal, da segunda. Tal antagonismo material precede e funda a subjetividade, ela mesma modalidade da matéria. Mas, se for assim, então o antagonismo não é uma estrutura ontologicamente invariável: o torna tal somente o ofuscamento idealista, que o transforma em espírito. Como tudo o que é material, ele pode ser modificado e curado - através do trabalho. Esta é, por assim dizer, a boa nova do materialismo. Uma frase famosa da Sagrada Família exprime com simplicidade sublime o nexo entre o momento passivo, corpóreo da subjetividade, e a necessidade de uma transformação prática do mundo: "Se o homem é formado pelas circunstâncias, será necessário formar as circunstâncias humanamente” (Marx-Engels 2003, $150)$.

Ora, o primado do ser sobre a consciência, assim entendido, é o desafio que Marx e Engels lançaram a Hegel, e com ele, a toda a tradição filosófica. Nas Teses sobre Feuerbach e na Ideologia Alemã, a filosofia deveria ceder o lugar por um lado à práxis, por outro à ciência. Mas a práxis necessita ainda da reflexão; e a ciência marxiana depois de 1845 é cada vez mais ciência da objetividade social: pressionado por outras urgências, o materialismo se desinteressa pela consciência. Isso pode explicar porque, ainda as tentativas marxistas mais sérias de acertar as contas com os problemas da subjetividade - e, portanto, da práxis - recaíram, antes de Adorno, nas posições do idealismo: por exemplo, com o "sujeito-objeto idêntico" de Lukács. Entrementes, o conceito hegeliano de Wissenschaft estava sendo minado pelo desenvolvimento de novas ciências burguesas, particularmente uma. Todo o debate filosófico-acadêmico do final do século dezenove é dominado pelo problema do psicologismo, isto é, a tentativa de fundar a lógica sobre a ciência empírica da consciência. Da aporia dessa tentativa - a contradição entre particularidade e universalidade das "leis do pensamento"- partirá Husserl; e das aporias do idealismo husserliano, Adorno (na Metacrítica da teoria do conhecimento). Mas para combater, por um lado, a teoria da consciência burguesa, e por outro, os resultados dogmáticos do marxismo ortodoxo, com suas consequências políticas, Adorno 
necessitava, então, de uma ciência materialista da consciência. Felizmente, ele a tinha à disposição.

\section{O PONTO DE FUGA DA DIALÉTICA NEGATIVA}

Já desde o seu primeiro projeto de habilitação, então recusado por Cornelius, Adorno tinha intuído que a teoria freudiana do inconsciente era a oportunidade, para o marxismo, de penetrar no sancta sanctorum da teoria do conhecimento ${ }^{20}$. Freud é, por assim dizer, o termo médio entre Marx e a filosofia. Sua metapsicologia, de fato, deduz precisamente a subjetividade a partir de um antagonismo pré-subjetivo, o conflito pulsional. Adorno fala da "origem do eu no não-eu" (Adorno 2009, 169-70). O próprio Eu é derivado no sentido mais concreto, isto é, no sentido histórico: ele surgiu ontogeneticamente e filogeneticamente - e, com o Eu, todas as instâncias das quais ele é portador: lógica, razão e verdade ${ }^{21}$. É propriamente este o ponto de partida da Dialética do Esclarecimento. Isso permite, por um lado, resolver em um sentido materialista os problemas imanentes da teoria do conhecimento, e, por outro lado, atribuir ao próprio marxismo o seu ponto de fuga mais radical. O que surgiu, de fato, pode também desaparecer. Escreve Adorno na Dialética negativa: "A verdade seria o ocaso [Untergang] do sujeito" (Adorno 2009, 162); “o espírito subjetivo também permanece uma categoria histórica, algo que surgiu, que se altera e é virtualmente perecível" (ivi, 256) ${ }^{22}$. E ainda mais explicitamente no final de um de seus últimos escritos, o ensaio Sobre Sujeito e Objeto. Aqui Adorno faz cintilar por um instante um argumento formidável, e talvez o único possível, contra o relativismo. A relatividade não pertenceria mais ao enunciado verdadeiro individual, mas, por assim dizer, à verdade em bloco, aquela que Adorno chama de "função cognoscitiva" [Erkenntnisfunktion]. A verdade, assim, pode ser ao mesmo tempo universal e histórica. Adorno discute aqui as antinomias do psicologismo, na versão sociologizante de Durkheim:

\footnotetext{
${ }^{20} \mathrm{O}$ conceito de inconsciente na doutrina transcendental da alma, em Adorno 2018. Para uma reconstrução atenta dessa "pré-história" do pensamento de Adorno, cf. Wolff 2006. Sobre a relação entre dialética negativa e metapsicologia freudiana, cf. em particular Whitebook 1995 e Safatle 2012. ${ }^{21}$ Cf. também, por exemplo, Adorno 2009, 227-8: “O eu [...] não é nada imediato, mas é ele mesmo também algo mediatizado, algo que emergiu [einVermitteltes, Entsprungenes], em termos psicanalíticos: uma ramificação da energia libidinal difusa [...].É por isso que as teorias analíticas sobre o supereu logo se estiolam,por maior que seja a audácia com a qual se dá o seu ponto de partida: de outro modo, elas também precisariam atacar o eu que tanto mimam".

${ }^{22}$ Grifo meu.
} 
A reflexão do sujeito sobre seu próprio formalismo é reflexão sobre a sociedade, com o paradoxo de que, de acordo com a intenção do último Durkheim, os formadores constitutivos [ou seja, as formas lógicas a priori, G.Z.] originam-se socialmente, embora, por outro lado - ponto em que pode insistir a teoria do conhecimento corrente - sejam objetivamente válidos; as argumentações de Durkheim os supõem já em cada proposição que demonstra seu caráter condicionado. Este paradoxo talvez seja expressão do cativeiro objetivo do sujeito dentro de si. A função cognoscitiva, sem a qual não haveria diferença nem unidade do sujeito, surgiu por sua vez. Ela consiste essencialmente naqueles formadores; na medida em que há conhecimento, este deve exercer-se de acordo com eles, mesmo ali onde se projeta para mais além deles. Eles definem o conceito de conhecimento. Não são no entanto absolutos, mas sim vieram a ser o que são da mesma forma que a função cognoscitiva como tal. Não é de todo impossivel que poderiam perecer. Predicar seu caráter absoluto poria como absoluta a função cognoscitiva, absoluto o sujeito; relativizá-los revogaria dogmaticamente a função cognoscitiva. $^{23}$ (Adorno 1995,199-200)

Que o sujeito possa perecer, "não é de todo impossível”. O pensamento de que Bergotte não está morto para sempre "não é completamente incrível”. Aqui é o resultado mais temerário, e confessado apenas em voz baixa, da dialética negativa. A possibilidade suprema é a superação do Eu: é a própria utopia. E o "núcleo racional” da prova ontológica está na experiência desta possibilidade, que se dá toda vez que o "continuum" tautológico da consciência é transcendido pela irrupção do objeto “em carne e osso". Em cada um desses momentos, o sujeito experimenta que a sua separação do objeto, se é real por um lado, por outro lado não é a última palavra, não é um dado metafísico: de fato, o próprio espírito é corpo. Na Introdução à Metacrítica, Adorno escreve que a crítica filosófica "não tem outra medida a não ser a destruição da aparência" (Adorno 2007, 86). Se interpretamos a "aparência" como recalque, então o movimento individual de "destruição" é muito mais do que simples "exercício" ou "contradição performativa". No instante em que o recalque cai, ele é reconhecido como tal, ou seja, como determinado, causado, efeito material; e as causas materiais, em princípio, podem ser eliminadas inteiramente. A mesma coisa se pode dizer em termos mais concretos. Em um aforismo de Minima Moralia dedicado a Freud, Adorno escreve: "Somente aquele que fosse capaz de determinar a utopia no cego prazer somático, que não possui nenhuma intenção e aplaca qualquer uma, seria capaz de uma ideia inabalável da verdade" (Adorno 1992, 52). E, em um lugar central da Dialética negativa, está dito que todo sofrimento é sofrimento físico, incluindo suas "formas de reflexão" espirituais; e, vice-versa, toda felicidade é, em última análise, prazer físico (Adorno 2009, 172-4). Adorno acolhe a ideia de Benjamin de que a "intenção" cognitiva deve "extinguir-se" em seu objeto; mas, com Freud, ele

${ }^{23}$ Tradução alterada. Grifo meu. 
interpreta esse movimento em sentido materialista, como gratificação pulsional sublimada. No prazer físico do impulso aplacado, que é "cego" e basta a si mesmo, o sujeito deve apenas imaginar que nenhum trauma intervenha mais para interromper tal prazer; e isso seria já o absoluto. A utopia é, tão simplesmente, o desaparecimento completo do sofrimento físico: e, enquanto físico, ele pode desaparecer. A consciência, que conhece sua própria origem no sofrimento, precisamente ao experimentar esse condicionamento experimenta, ao mesmo tempo, a possibilidade do “ocaso". À crítica dialética da razão, portanto, não falta um critério, como Habermas gostaria. Um único ato falho já é a prova ontológica no seu "núcleo racional".

\section{O QUE PODERIA SER EFETIVAMENTE FALSO EM HEGEL}

E, todavia, se o "ocaso" do sujeito no objeto é uma experiência que fazemos continuamente, isso não é ainda o "ocaso" no sentido da utopia: o "sucesso". Daí a necessidade da passagem para a práxis. Voltemos assim aos Três Estudos e ao problema de Hegel, e concluamos, provisoriamente, o nosso argumento.

Justamente em Aspectos, Adorno afronta de modo mais extenso o problema ao redor do qual temos até então girado sem quase mencioná-lo, e que, na realidade, é o fulcro teórico do materialismo: o problema do trabalho. Adorno o define como "o segredo" do idealismo (Adorno 2015a, 66). O trabalho, no seu pensamento, é o verdadeiro conceito intermediário entre a esfera imanente, teórico-cognitiva, e a esfera prático-real. De fato, o nervo vital não apenas dos Três Estudos, mas da dialética negativa inteira, a sua novidade, consiste precisamente nesta tese tríplice: 1) o espírito é trabalho; 2) o trabalho é negatividade; 3) a negatividade pode ser eliminada. Adorno retoma a interpretação marxiana da apercepção transcendental como trabalho socialmente organizado, e prossegue: Hegel, ao determinar o espírito como atividade pura, ao mesmo tempo reconheceu corretamente o espírito como trabalho e recalcou o momento natural, não idêntico, sobre o qual o trabalho se exerce. Como consequência, recalcou também o momento da coerção, do sofrimento que pertence a todo trabalho, mesmo ao espiritual, enquanto luta contra uma resistência, e transformou a necessidade em liberdade. A falsidade de Hegel seria a apologia burguesa do trabalho. O trabalho, para ele, torna-se o "absoluto" em duplo sentido: o positivo e o insuperável. Estas páginas de Adorno estão entre as suas mais importantes: 
Já a tão tradicional distinção entre sensibilidade e intelecto indica que o intelecto, em contraste com o que é dado apenas pela sensibilidade, faria algo como um obséquio sem contrapartida: o dado sensível seria como as frutas no campo, mas as operações do entendimento ficariam à mercê do arbítrio; elas poderiam acontecer ou serem omitidas [...]. O comportamento do pensamento como tal é indiferente ao que ele possui como conteúdo, é confronto com a natureza tornado habitual e interiorizado; intervenção, não mera recepção. É por isso que o discurso sobre o pensamento em geral vem junto de um discurso sobre algo material do qual o pensamento é separado, tal como o trabalho faz com sua matéria prima. De fato, todo pensamento está unido a esse momento de tensão violenta - reflexo das necessidades vitais - que caracteriza o trabalho; labuta e esforço do conceito não são metafóricos. ${ }^{24}$ (Adorno 2015a, 68)

A metáfora evangélica das "frutas no campo" ilustra da melhor maneira o que Adorno quer dizer com a oposição entre "intervenção" e "mera recepção". A utopia da mera recepção é precisamente o que permanece cortado da totalidade hegeliana. Se quiséssemos agora arriscar uma resposta à nossa pergunta inicial, e definir o que é falso em Hegel sem recair aquém da dialética, talvez a formulação mais eloquente seja precisamente esta: o conceito hegeliano de espírito exclui a priori que as frutas no campo poderiam ser simplesmente dadas. Para exprimir o mesmo conceito de um outro lado: a guerra é o horizonte não transcendível da filosofia hegeliana da história, ao passo que já Kant - como observa Adorno no aforisma "Surl'eau" de Minima Moralia - chegou até conceber a utopia da paz perpétua ${ }^{25}$. O impulso de superar todo limite, essência da filosofia tanto de Hegel como de Nietzsche, é um impulso de emancipação: toda vitória do Eu sobre o não-Eu já é plena libertade, é o "sucesso"; e é sempre possível. Esta é verdade de Hegel. Mas a Ideia absoluta, tal como o super-homem, é ainda uma figura do mundo irreconciliado. O Eu absolutizado é condenado a novamente recomeçar a luta toda vez, miticamente, e sua infinitude interverte na posição de um novo limite: a própria existência de um limite a superar. Em vez disso, o mundo que Adorno chama de "conciliado" consistiria em uma objetividade transformada: implicaria o desaparecimento de toda necessidade real e, assim, da luta necessária contra a realidade, aquela que Adorno chama de "tensão violenta". Seria a abolição da necessidade do trabalho, incluindo aquele trabalho particular que é o pensamento. Pois, como diz Adorno, "uma humanidade livre do trabalho seria uma humanidade livre da dominação" (Adorno 2015a, 72). Assim deve ser entendida a tese de superação do Eu.

Precisamente essa tese, entretanto, ainda dá razão a Hegel por uma última vez. Depois de Adorno, a superação do Eu tornou-se muito popular filosoficamente, com rótulos como

\footnotetext{
${ }^{24}$ Tradução alterada.

${ }^{25}$ Cf. Adorno 1992, 138; Adorno 2009, 280-2.
} 
“dessubjetivação". O dialético Adorno desmentiu antecipadamente tais veleidades e, escutando a fundo o que o irracionalismo tem a dizer, erigiu o mais poderoso bastião em defesa da razão. A superação do Eu é o ponto de fuga, não o aqui e agora. O sujeito não pode escolher revogar a si próprio: este ato de vontade o perpetuaria, e, além disso, o jogaria em cima do obscurantismo. O que ele poderia fazer é humanizar o mundo, de modo que isso relaxe seus efeitos sobre os "seres objetivos" que virão, até, por fim, tornar gradualmente supérflua a própria existência de um sujeito. Seu desaparecimento deveria ser entendido como uma "extinção", no sentido em que Engels falava da extinção do Estado. Da perspectiva do seu fim, o Eu traz, dialeticamente, sua própria legitimidade: se o Eu surgiu a partir de um conflito présubjetivo, ele certamente reproduz esse conflito em si, e tende justamente à sua própria superação na "reconciliação"; mas é também, por assim dizer, absolvido da responsabilidade originária pela negatividade. Aquém da reconciliação, o sujeito conserva todas as prerrogativas pelas quais ele nasceu, e representa efetivamente o mais elevado baluarte da liberdade. Esta duplicidade é a duplicidade do trabalho. Serve o Eu para superar o Eu, pois serve o trabalho para superar o trabalho: "Mas o repouso do movimento, o absoluto, ao final significa também para [Hegel] senão a vida reconciliada, a do impulso saciado, que não conhece mais nenhuma carência nem o trabalho, ao qual no entanto ele deve sua reconciliação" (Adorno 2015a, 76) ${ }^{26}$.

Essa é a figura mais própria do pensamento de Adorno. Não se trata, como afirma Habermas, de um olhar retrospectivo, que anela desesperadamente a salvar aquilo que já se sabe perdido; mas de uma ponte jogada adiante, com a razão e de dentro da razão, para o seu outro. É a figura que Adorno, nos Três Estudos, empresta do Parsifal: "a ferida só é curada com a lança que a causou" (Adorno 2015a, 106). Assim, Adorno verdadeiramente leva adiante o legado do pensamento ocidental, "no instante de sua queda" (Adorno 2009, 337). Não há fé maior na razão, não há tributo mais alto ao espírito que o julgá-lo capaz até de superar a si mesmo.

\section{SOBRE UM POSSÍVEL RESULTADO PRÁTICO}

Isto vale para todas as expressões da abstração "burguesa”: Eu, conceito, razão, verdade; e mesmo Estado e direito. Não podemos aprofundar aqui a tese da abolição do trabalho, tal como poderia ser deduzida a partir das premissas adornianas; limitemo-nos, então, a

${ }^{26}$ Grifo meu. 
uma menção rápida. A “abolição do trabalho" (ou melhor, da necessidade do trabalho) não designa, aqui, uma possibilidade imediata - como em certas teorias pós-operaistas da "renda básica incondicional “-, muito menos uma condição que, em algum sentido, estaria já dada atualmente - como no diagnóstico de Robert Kurz de um "fim do trabalho"27. Pelo contrário, ela deve ser entendida como um possível processo dialético de abolição do trabalho através do trabalho. Essa dialética prática seria também negativa, pois aquilo que deveria ser "produzido" por um tal trabalho não seria, diretamente, o conteúdo positivo da utopia, mas a mera eliminação da condição que a torna impossível. Por isso, nesta leitura da dialética negativa, a abolição tendencial da necessidade do trabalho representa - em um sentido que vai para além do próprio Marcuse - o verdadeiro ponto arquimediano, a mediação prática entre o presente e a utopia. De fato, como essa abolição deve e pode ser posta pela vontade e organizada, ela ainda é uma expressão do Eu racional; mas abre, ao mesmo tempo, a extinção do Eu. O que significa, no entanto, que o trabalho social deveria poder ser dirigido em direção à sua abolição, e isso pressupõe, por sua vez, que a produção social, como um todo, seja planificada racionalmente; com todas as consequências desse pressuposto.

A abolição do trabalho enquanto postulado prático, portanto, resolve, na teoria, um problema crucial da história recente, o do assim chamado "Estado de direito socialista", isto é: como seria possível superar a anarquia da produção sem recair na dominação imediata, mas, pelo contrário, pressupondo o Estado de direito. A abolição do trabalho como uma meta coletiva legitimaria a coerção de cada indivíduo ao trabalho, justamente por ser baseada no conceito burguês do direito. Ela não pretenderia realizar diretamente a "liberdade substancial", a unidade plena entre homens ou, em termos adornianos, o "sujeito global[Gesamtsubjekt]" (Adorno 2009, 253), o qual poderia dar-se somente de maneira espontânea, e não ser posto pela vontade. Em vez disso, seria tomada ao pé da letra a ideia burguesa da liberdade como liberdade negativa. Reconhecendo que o poder material sobre o trabalho de outros é uma limitação desta mesma liberdade e deveria ser abolido em nome dela, a meta do Estado de direito está posta, coerentemente, numa coerção ao trabalho limitada e regulada, que tenda à sua própria máxima redução possível e, virtualmente, à sua eliminação. Vice-versa - e pelo mesmo motivo - a organização social do trabalho como o processo dialético-negativo de sua própria superação não pode ser pensada sem o Estado de direito: a defesa intransigente das liberdades do indivíduo.

${ }^{27}$ Cf. Kurz 2008. 
Desta maneira começam a tornar-se visíveis as consequências práticas da dialética negativa, que Adorno prudentemente deixou implícitas. Se o seu pensamento filosófico teve conteúdo político, este é a refutação do anarquismo. Daí que a dialética negativa traz toda sua seriedade. Ela diz que aquilo que falhou uma vez pode dar certo realmente - e não apenas na imaginação -“dochnoch”: "ainda, malgrado tudo". De resto, o que Adorno sempre teve em mente, revela-o o olhar mais rápido em seus escritos programáticos. 1931, A Atualidade da Filosofia: "Seriedade significa, aqui, que a resposta não está no espaço fechado do conhecimento, mas é a práxis que a dá. [...] Da construção da figura da realidade segue imediatamente a exigência de sua transformação real [realeVeränderung]" (Adorno 1977, 129). 1956, Introdução à Metacrítica: a própria dialética "seria superada somente através de uma práxis transformadora [veränderndePraxis]" (Adorno 2007, 86). 1966, abertura da Dialética negativa: "A filosofia, que um dia pareceu ultrapassada, mantém-se viva porque se perdeu o instante de sua realização" (frase que pressupõe, evidentemente, o conceito de "realização da filosofia"); e, por outro lado, "o pensamento crítico" deveria servir à "práxis transformadora" (Adorno 2009, 11). E, enfim, mais adiante, no centro especulativo da obra: "O momento corporal anuncia ao conhecimento que o sofrimento não deve ser, que ele deve mudar. 'Adorno diz: pereça'. Por isso, o especificamente materialista converge com aquilo que é crítico, com a práxis socialmente transformadora [mitgesellschaftlichverändernderPraxis]" (ivi, 173).

Pode ter sido uma "mensagem colocada na garrafa", segundo uma expressão de Horkheimer, que desde então ama-se repetir ${ }^{28}$. Mas era uma garrafa incendiária.

${ }^{28} C f$. carta de Horkheimer a SalkaViertel em 1940, apud Müller-Doohm 2005, 262. 


\section{REFERÊNCIAS}

Adorno, Theodor W. (1973). PhilosophischeTerminologie. 2 voll. Frankfurt a.M.: Suhrkamp. (1977). The Actuality of Philosophy. “Telos", 31, pp. 120-33. (1991). Notes to Literature. Vol. 1. Trad. S. Weber Nicholsen. New

York: Columbia University Press. (1992). Minimamoralia. Reflexões a partir da vida danificada.

Trad. L.E. Bicca, rev. G. de Almeida. São Paulo: Ática. (1995). Palavras e sinais. Modelos críticos 2. Trad. M.H. Ruschel.

Petrópolis: Vozes. (2007). Para a metacrítica da teoria do conhecimento. Estudos sobre Husserl e as antinomias fenomenológicas. Trad. M.A. Casanova, rev. E. Socha. São Paulo: Editora UNESP.

(2009). Dialética negativa. Trad. M.A. Casanova, rev. E. Soares

Neves da Silva. Rio de Janeiro: Jorge Zahar. (2010). Einführung in die Dialektik. Ed. C. Ziermann. Frankfurt a.M.: Suhrkamp. (2015a). Três Estudos sobre Hegel. Trad. F. López Toledo Corrêa. Dissertação de Mestrado não publicada. UNIFESP (SP). (2015b). Ensaios sobre psicologia social e psicanálise. Trad. V. Freitas. São Paulo: Editora UNESP. (2018). Primeiros escritos filosóficos. Trad. V. Freitas. São Paulo:

Editora UNESP.

Arantes, Paulo Eduardo (1990). Tentativa de identificação da Ideologia Francesa. Uma introdução. "Novos Estudos", 28, pp. 74-98.

Benjamin, Walter (2008). A tarefa do tradutor, em: L. Castello Branco (org.). A tarefa do tradutor, de Walter Benjamin: quatro traduções para o português. Belo Horizonte: Fale/UFMG.

Bowie, Andrew (2013). Adorno and the Ends of Philosophy. Cambridge (UK): Polity Press.

Buck-Morss, Susan (1977). The Origin of Negative Dialectics. Theodor W. Adorno, Walter Benjamin, and the Frankfurt Institute. New York: The Free Press. 
(1985). Die neue Unübersichtlichkeit. Frankfurt a.M.: Suhrkamp.

Habermas, Jürgen (1999). Teoria de la acción comunicativa. Vol. 1. Trad. M. Jiménez Redondo. Madrid: Taurus.

(2000). O discurso filosófico da modernidade. Trad. L.S. Repa, R. Nascimento. São Paulo: Martins Fontes.

Jaeggi, Rahel (2005). »Kein Einzelner vermag etwas dagegen«. Adornos Minima moraliaals Kritik von Lebensformen, in: A. Honneth (ed.), Dialektik der Freiheit. Frankfurter Adorno-Konferenz 2003. Frankfurt a.M.: Suhrkamp, pp. 115-141.

Kurz, Robert (2008). O colapso da modernização. Da derrocada do socialismo de caserna à crise da economia mundial. Trad. K. Elsabe Barbosa. São Paulo: Paz e Terra.

Marx, Karl (2004). Manuscritos econômico-filosóficos. Trad. J. Ranieri. São Paulo: Boitempo.

Marx, Karl; Engels, Friedrich (2003). A sagrada família ou A crítica da Crítica crítica (contra Bruno Bauer e consortes). Trad. M. Backes. São Paulo: Boitempo.

Müller-Doohm, Stefan (2005). Adorno. A Biography. Trad. R. Livingstone. Cambridge (UK): Polity Press.

Nuzzo, Angelica (2008). Dialettica negativa e dialettica speculativa. Adorno ed Hegel.

Em: L. Pastore, T. Gebur (org.). Theodor W. Adorno. Il maestro ritrovato. Roma: manifestolibri, pp. 154-80.

O’ Connor, Brian (2004). Adorno's Negative Dialectic. Philosophy and the Possibility of Critical Rationality. Cambridge (Mass.), and London: The MIT Press.

Petrucciani, Stefano (2004). Un pensiero sul margine del paradosso. Em: Th. W. Adorno, Dialettica negativa. Torino: Einaudi, pp. XI-XXVII.

Reichelt, Helmut (2008): Oggettività sociale e critica dell'economia politica: Adorno e Marx. Em: Theodor W. Adorno. Il maestro ritrovato, cit., pp. 223-41.

Safatle, Vladimir (2012). Grande Hotel Abismo. Por uma reconstrução da teoria do reconhecimento. São Paulo: Editora WMF Martins Fontes.

Sherratt, Yvonne (2007). Adorno's Positive Dialectic. Cambridge (UK): Cambridge University Press.

Sommer, Marc Nicolas (2016). Das Konzept einer negativen Dialektik. Adorno und Hegel. Tübingen: Mohr Siebeck.

Whitebook, Joel (1995). Perversion and Utopia. A Study in Psychoanalysis and Critical Theory. Cambridge (Mass.): The MIT Press. 
Wolff, Ernst (2006). From Phenomenology to Critical Theory. The Genesis of Adorno's Critical Theory from his Reading of Husserl. "Philosophy and Social Criticism", 32, pp. 55572.

Zanotti, Giovanni (2015). Objective Being as Non-Identity. On Marx's and Adorno's Critiques of Hegel. "Hegel-Jahrbuch", pp. 232-40.

(2016). Contingent Antagonism. A Key to Adorno's Dialectic.

“Discipline filosofiche”, XXVI, 2, pp. 139-50. 


\section{AGRADECIMENTOS}

O presente trabalho foi realizado com apoio da Coordenação de Aperfeiçoamento de Pessoal de Nível Superior - Brasil (CAPES) - Código de Financiamento 001. 